\title{
Demand for exercise training in patients with pulmonary arterial hypertension in Scotland
}

\author{
To the Editor:
}

Despite significant advances in medical therapy, most patients with pulmonary arterial hypertension (PAH) remain symptomatic on treatment [1]. The recently published UK PAH national audit 2014 [2] demonstrates a $65 \%$ rate of failure of monotherapy at 2 years. New treatment strategies are therefore essential to improve morbidity and, if possible, mortality.

Over the past 10 years, the body of evidence supporting exercise training as an effective treatment for PAH has grown significantly, such that the 2013 consensus statement on the management of PAH upgraded its recommendation to class $\mathrm{I}$, level $\mathrm{A}$. This has been reinforced recently in a detailed review from the Heidelberg group which summarised the evidence for this intervention [3].

The consensus statement and review recommended that exercise training of PAH patients should be undertaken by centres experienced in both the management of $\mathrm{PAH}$ and rehabilitation of compromised patients. Despite this, dedicated exercise training programmes do not exist in the UK and many other European countries. In these countries, exercise training is delivered to a small, unselected population of pulmonary hypertension patients in an ad hoc manner, by services specialised for chronic obstructive pulmonary disease or left heart failure.

Several factors may hinder the widespread adoption of specialised exercise training for patients with PAH. First, the infrastructure and expertise that exists in German rehabilitation clinics, where much of this research has been conducted, does not exist in many other centres, raising the question of whether these results can be replicated elsewhere. Secondly, the successful approach described by MERELES et al. [4] involved an initial intense inpatient phase followed by a monitored outpatient period, using multimodality, PAH specific rehabilitation. Such an approach is demanding both on patient time and hospital resources. The optimal structure for a rehabilitation programme has not been established and other investigators have evaluated less intensive strategies. DE MAN et al. [5] utilised existing outpatient cardiac rehabilitation facilities and observed improved muscle endurance but failed to show an improvement in 6-min walk distance (6MWD), suggesting that there are advantages to the inpatient approach. Finally, no long-term data exist to support a prognostic benefit.

In order to establish a training programme for $\mathrm{PAH}$, it must first be determined that there is demand among the patient population for such a treatment. With this in mind, we surveyed patient interest and willingness to participate in a programme of intensive inpatient rehabilitation, followed by outpatient rehabilitation, mirroring that of Mereles et al. [4].

The Scottish Pulmonary Vascular Unit (SPVU) in Glasgow, UK serves a population of 5.3 million and is the national referral centre for PAH in Scotland, with a prevalent population of 47 per million [2].

In our cohort, we contacted 224 patients with PAH. We included the following patients: 1) World Health Organization functional class I-III; 2) $6 \mathrm{MWD} \geqslant 150 \mathrm{~m}$; and 3) $\mathrm{PAH}$ diagnosed by right heart catheterisation (mean pulmonary artery pressure $\geqslant 25 \mathrm{mmHg}$, pulmonary capillary wedge pressure $\leqslant 15 \mathrm{mmHg}$ and pulmonary vascular resistance $>3$ Wood units).

$43 \%$ of patients (96 out of 224 ) responded to the survey. $62.5 \%$ (60 out of 96 ) were interested in all components of the rehabilitation programme (inpatient and outpatient); a further $11.5 \%$ (11 out of 96) were interested in outpatient rehabilitation only.

Those interested tended to be younger and were in a better functional class. There was no significant difference between groups in haemodynamics, quality of life or N-terminal pro-brain natriuretic peptide (table 1).

Additionally, patients provided free text responses. Many reported enthusiasm towards the proposal and felt it would improve their confidence, overall health and quality of life. The following reasons were cited in patients who felt at least one aspect of the programme would be unsuitable: 1) too far from home, $19.4 \%$ (seven out of 36$)$; 2) work or carer commitment, $27.8 \%$ (10 out of 36$)$; 3) too old or too many comorbidities, $27.8 \%$ (10 out of 36 ); 4) too big a time commitment, 5.6\% (two out of 36 ); 5) active enough, $8.3 \%$ (three out of 36 ); 6) equipment in their house would be unacceptable, $2.8 \%$ (one out of 36); and 7) no reason given, $8.3 \%$ (three out of 36 ). 
TABLE 1 Characteristics of those interested in rehabilitation versus those not interested

\begin{tabular}{|c|c|c|c|}
\hline & “No" responders & “Yes" responders & p-value \\
\hline \multicolumn{3}{|l|}{ Haemodynamic } & \\
\hline mPAP $\mathrm{mmHg}$ & $45.3 \pm 12.5$ & $44.7 \pm 14.4$ & NS \\
\hline $\mathrm{SvO}_{2} \%$ & $64.1 \pm 8.9$ & $64.7 \pm 8.6$ & NS \\
\hline Thermodilution $\mathrm{CO} L \cdot \mathrm{min}^{-1}$ & $4.5 \pm 1.3$ & $4.7 \pm 1.6$ & NS \\
\hline \multicolumn{4}{|l|}{ Functional } \\
\hline CAMPHOR total & $26.0 \pm 19.4$ & $31.6 \pm 18.2$ & NS \\
\hline QOL & $7.2 \pm 6.7$ & $10.0 \pm 7.9$ & NS \\
\hline Activities & $10.8 \pm 6.4$ & $10.6 \pm 6.1$ & NS \\
\hline Symptoms & $9.3 \pm 7.1$ & $11.2 \pm 6.8$ & NS \\
\hline EMPHASIS & $22.1 \pm 15.2$ & $25.5 \pm 11.6$ & NS \\
\hline 6-min walk distance $\mathrm{m}$ & $348 \pm 129$ & $381 \pm 111$ & NS \\
\hline Age years & $68.1 \pm 13.1$ & $56.4 \pm 13.3$ & 0.0008 \\
\hline NTproBNP & $1250 \pm 1901$ & $788 \pm 976$ & NS \\
\hline Male & $53.3 \%(16 / 30)$ & $45 \%(27 / 60)$ & NS \\
\hline \multicolumn{4}{|l|}{ Disease category } \\
\hline IPAH & $23 \%(7 / 30)$ & $34.5 \%(20 / 58)$ & NS \\
\hline CTD-PAH & $30 \%(9 / 30)$ & $12.1 \%(7 / 58)$ & \\
\hline $\mathrm{CHD}-\mathrm{PAH}$ & $6.7 \%(2 / 30)$ & $12.1 \%(7 / 58)$ & \\
\hline $\mathrm{POPH}$ & $6.7 \%(2 / 30)$ & $6.9 \%(4 / 58)$ & \\
\hline CTEPH & $30 \%(9 / 30)$ & $24.1 \%(14 / 58)$ & \\
\hline HIV-PAH & $0 \%$ & $1.7 \%(1 / 58)$ & \\
\hline PVOD & $0 \%$ & $3.4 \%(2 / 58)$ & \\
\hline Group 5 & $3.3 \%(1 / 30)$ & $5.2 \%(3 / 58)$ & \\
\hline \multicolumn{4}{|l|}{ WHO FC } \\
\hline Group I & $0 \%(0 / 30)$ & $12.2 \%(7 / 57)$ & 0.047 \\
\hline Group II & $70 \%(21 / 30)$ & $47.4 \%(27 / 57)$ & \\
\hline Group III & $30 \%(9 / 30)$ & $40.4 \%(23 / 57)$ & \\
\hline Oxygen therapy & $15.6 \%(5 / 32)$ & $5.0 \%(3 / 60)$ & NS \\
\hline
\end{tabular}

Data are presented as mean $\pm \mathrm{SD}$, unless otherwise stated. mPAP: mean pulmonary artery pressure; $\mathrm{SvO}_{2}$ : mixed venous oxygen saturation; CO: cardiac output; QOL: quality of life; NTproBNP: N-terminal pro-brain natriuretic peptide; IPAH: idiopathic pulmonary arterial hypertension; CTD: connective tissue disease; CHD: congenital heart disease; POPH: portopulmonary hypertension; CTEPH: chronic thromboembolic pulmonary hypertension; PVOD: pulmonary veno-occlusive disease; WHO FC: World Health Organization functional class; NS: nonsignificant.

Our data demonstrate considerable enthusiasm to pursue exercise training as a treatment, even when it involves an inpatient stay. This level of interest, in addition to the growing body of evidence supporting the beneficial effects of exercise, suggests that strong consideration should be given to establishing access for all patients with $\mathrm{PAH}$ to dedicated rehabilitation services as a routine element of their care.

In our population, those with poorer functional class or significant comorbidity were less likely to participate in rehabilitation. Even in patients with severe PAH, exercise training is safe and beneficial. A concerted effort must be made to ensure patients with a higher burden of disease are reassured and efforts are made from a logistical and rehabilitation perspective to make such an intervention more acceptable. This requires further research to establish the optimal components of a $\mathrm{PAH}$ rehabilitation programme and how it might be successfully modified for more compromised individuals.

$@$ ERSpublications

Scottish patients with PAH wish to take part in dedicated and intensive exercise rehabilitation programmes http://ow.ly/Owwai

Alison MacKenzie and Martin Johnson

Scottish Pulmonary Vascular Unit, Glasgow, UK.

Correspondence: Alison MacKenzie, Scottish Pulmonary Vascular Unit, Glasgow, UK. E-mail: alisonmackenzie2@nhs.net

Received: May 072015 | Accepted after revision: May 28 2015 | First published online: July 232015

Conflict of interest: Disclosures can be found alongside the online version of this article at erj.ersjournals.com 


\section{References}

1 Galie N, Corris PA, Frost A, et al. Updated treatment algorithm of pulmonary arterial hypertension. J Am Coll Cardiol 2013; 62: Suppl. 25, D60-D72.

2 Gibbs JS. National Audit of Pulmonary Hypertension 2014. Health and Social Care Information Centre, 2015. www.hscic.gov.uk/catalogue/PUB17264/nati-pulm-hype-audi-2014-rep.pdf

3 Marra AM, Egenlauf B, Bossone E, et al. Principles of rehabilitation and reactivation: pulmonary hypertension. Respiration 2015; 89: 265-273.

4 Mereles D, Ehlken N, Kreuscher S, et al. Exercise and respiratory training improve exercise capacity and quality of life in patients with severe chronic pulmonary hypertension. Circulation 2006; 114: 1482-1489.

5 de Man FS, Handoko ML, Groepenhoff $\mathrm{H}$, et al. Effects of exercise training in patients with idiopathic pulmonary arterial hypertension. Eur Respir J 2009; 34: 669-675.

\section{How does a new breathlessness support service affect patients?}

To the Editor:

Breathlessness is a highly prevalent and distressing symptom in advanced disease but there is uncertainty about its treatment. Patients with breathlessness have complex needs, on average experience 13-14 other symptoms (such as pain, fatigue, sleep problems and depression) and frequently attend emergency hospital services [1]. As the best way of organising and delivering a service for the relief of breathlessness is not known, an interdisciplinary service was developed for patients with breathlessness in advanced disease and their carers: the Breathlessness Support Service (BSS) [2]. Here, we report the results of qualitative interviews of patients who received the BSS.

The BSS is distinct from previous services $[3,4]$ with respect to the incorporation of respiratory expertise, the widening of the range of professionals in the team and its primary mode of delivery in the outpatient clinic, with two appointments and a home visit within 4 weeks. At the first clinic visit, patients were assessed by respiratory medicine and palliative care clinicians and an individualised plan of treatment was agreed. They received a breathlessness pack with information, management and pacing guidance, a poem (to help breathing and relaxation during crises), a hand-held fan or water spray and an individualised crisis plan. A home assessment after 2-3 weeks was performed by a respiratory physiotherapist and/or occupational therapist, who developed a tailored programme based on the domestic situation of the patient. If needed, they referred the patient to rehabilitation or a social worker. After the second and final clinic visit, further individualised actions and a discharge plan were agreed. Summaries of both clinic visits were sent to the individual, with a copy to their general practitioner and referring staff $[2,5]$.

The BSS was evaluated by a randomised controlled trial (RCT) [5], according to the Medical Research Council Framework for complex interventions. The BSS significantly improved self-rated quality of life and the way patients managed their breathlessness, as assessed by breathlessness mastery. Patients recorded their mastery, and its effects on quality of life and function. Patients also had better survival, as a secondary outcome $[6,7]$. The qualitative findings of the mixed-methods evaluation shed light on the components of the BSS, its mechanisms and how patients experienced the intervention.

The outpatient clinic of the BSS was based in the Cicely Saunders Institute at King's College Hospital in Southeast London, UK. 105 patients consented and were randomised for the trial [5]. Ethics approval was granted by the King's College Hospital Research Ethics Committee (reference 10/H0808/17). The study met the requirement of the local Research Governance Framework. All patients provided informed consent.

A researcher conducted interviews with a subsample of patients, 12 weeks after initially receiving the BSS. All interviews took place at the patients' homes, except one in a nursing home. The interviews were semi-structured and in-depth. A topic guide was used to ensure that all relevant topics were systematically covered (table 1). Interviews were tape-recorded and transcribed verbatim. Demographic data and clinical information were collected in the context of the RCT. Analysis was performed first by reading and coding the transcribed interviews. From the data, themes/categories were derived through an inductive approach. 